\title{
Focal nodular hyperplasia of the liver associated with intracranial vascular malformations
}

\author{
R D Goldin, D S C Rose
}

\begin{abstract}
Focal nodular hyperplasia of the liver, neoplasia of the brain, and intracranial vascular malformations have recently been described as a new syndrome. We report three cases of focal nodular hyperplasia of the liver with intracranial vascular anomalies. Two patients died from ruptured berry aneurysm. It is important to consider intracranial pathology in patients with focal nodular hyperplasia of the liver.
\end{abstract}

Focal nodular hyperplasia of the liver is an uncommon benign lesion comprising an area of hyperplastic hepatic parenchyma around a fibrous 'scar' containing a feeding artery and a variable number of proliferating bile ducts. The lesion is circumscribed, with compression of surrounding tissue. The lesions vary in size from a few millimetres to more than $15 \mathrm{~cm}$ in diameter and may be single or multiple. They are generally incidental findings on clinical examination, operation or autopsy. Occasionally focal nodular hyperplasia of the liver may present as a result of abdominal fullness, pain, or haemorrhage, sometimes in young women on the contraceptive pill. ${ }^{1}$ Nodules are rarely found on imaging the liver for other reasons. The pathogenesis of focal nodular hyperplasia of the liver is not known, but after studying 36 cases, and a review of the literature, Wanless and colleagues ${ }^{2}$ concluded that the lesion results from a hyperplastic response of the hepatic parenchyma to a developmental arterial malformation. Wanless' group have recently suggested a syndrome comprising multiple focal nodular hyperplasia of the liver, vascular malformation, and neoplasia of the brain and meninges. ${ }^{3}$ The seven patients in their series included one with a berry aneurysm. In the light of this, we have reviewed our post mortem records and report three patients with focal nodular hyperplasia of the liver associated with intracranial vascular malformation, two of whom died from rupture of a berry aneurysm.

\section{Patient 1}

A 57 year old man was admitted having developed a sudden onset headache followed by rapid loss of consciousness. He died shortly afterwards. At necropsy the liver weighed $1590 \mathrm{~g}$ and revealed the presence of three lesions; two nodules, the larger $4 \mathrm{~cm}$ in diameter, the smaller $2.5 \mathrm{~cm}$ diameter, both in the right lobe, and both having an irregular pale area at their centres, and a haemangioma $3.5 \mathrm{~cm}$ in diameter, also in the right lobe, but separate from the other two lesions. On examination there were two berry aneurysms, one $1 \mathrm{~cm}$ in diameter, arising from the anterior communicating artery, which had ruptured into the surrounding brain, and a second arising from the left half of the posterior communicating artery. There were no other abnormalities. Histology of the liver lesions showed the typical histological features of focal nodular hyperplasia of the liver described above.

\section{Patient 2}

A 46 year old woman was admitted in coma and died without regaining consciousness. At necropsy the liver weighed $1200 \mathrm{~g}$ and contained a well defined pale lesion $6 \mathrm{~cm}$ in diameter located in the left lobe with a fibrous core which was confirmed as focal nodular hyperplasia of the liver on histology. The cause of death was a ruptured berry aneurysm arising from the right anterior cerebral artery with extensive subarachnoid haemorrhage and intraventricular extension.

\section{Patient 3}

A 65 year old woman who died after intraventricular cardiac rupture as a result of myocardial infarction. Necropsy revealed fibrinous pericarditis, an infarct of the anterior wall of the left ventricle, and an interventricular septal rupture. The liver weighed $1500 \mathrm{~g}$ and had a $0.5 \mathrm{~cm}$ yellow nodule and a separate $0.4 \mathrm{~cm}$ haemangioma in the right lobe. The cerebral arteries showed a moderate amount of atheroma and there was a small lesion in the left occipital lobe. The histology showed myocardial infarction, a small focus of focal nodular hyperplasia of the liver, and capillary telangiectasis in the occipital cortex.

\section{Discussion}

Focal nodular hyperplasia of the liver is usually merely a diagnostic puzzle although it may rarely cause severe hepatic bleeding. The treatment may be conservative, or the feeding arteries may be embolised (personal communication, R Dick, Royal Free Hospital, London), or ligated. ${ }^{4}$ Surgical resection may be attempted, although this has a risk of death ${ }^{56}$ which may not be justified if patients have an asymptomatic mass or mild symptoms.

The intracranial manifestations, however, are potentially fatal. Most berry aneurysms rupture, ${ }^{7}$ and subarachnoid haemorrhage carries a mortality of $45 \%$ in the first two months. ${ }^{8}$ Even in adult polycystic renal disease, the most common serious condition associated with berry aneurysms, $8 \%$ of patients do not die from renal failure, but from subarachnoid haemor- 
rhage. ${ }^{9}$ Of the seven cases cited in the description of the new syndrome by Wanless' group, ${ }^{3}$ one had a berry aneurysm, and one telangiectasis of the pons. The other associations were of malignant and non-malignant intracranial tumours. Clustering of vascular abnormalities and malignancy occurs in von Hippel-Lindau disease.

In conclusion, we present three cases of focal nodular hyperplasia of the liver, two of whom died from rupture of berry aneurysm. Our findings support the existence of the syndrome described by Wanless and suggest that intracranial pathology should be actively considered in patients with focal nodular hyperplasia of the liver.
1 Mays ET, Christopherson WM, Barrows GH. Focal nodular hyperplasia of the liver. Possible relationship to oral contra ceptives. Am 7 Clin Pathol 1974; 61: 735-46.

2 Wanless IR, Mawdsley C, Adams R. On the Pathogenesis of Focal Nodular Hyperplasia of the Liver. Hepatology 1985; 5 : 1194-200.

3 Albrecht S, Wanless IR, Bilbao J, Frei JV. Multiple focal nodular hyperplasia of the liver associated with vascula malformations and neoplasia of the brain and meninges: new syndrome. Lab Invest 1989; 60: 2 A

4 Mowat AP, Gutjahr P, Portmann B, Dawson JL, Williams R. Focal nodular hyperplasia of the liver: a rational approach to treatment. Gut 1976; 17: 492-4.

5 Kay S, Talbert PC, Adenoma of the liver, mixed type (hamartoma). Cancer 1950; 3: 307-15.

6 Whelan TJ, Baugh JH, Chandor S. Focal nodular hyperplasia of the liver. Ann Surg 1973; 177: 150-8.

7 Walton J. Aneurysm of congenital origin. In: Walton J. Brain's diseases of the nervous system. Oxford: Oxford University

8 Walton JN. In: Walton JN. Subarachnoid haemorrhage Edinburgh, London: E\&S Livingstone Ltd, 1956: 173.

9 Segal AJ, Spataro RF, Barbaric ZL. Adult polycystic kidney disease: a review of 100 cases. $\mathcal{F}$ Urol 1977; 118: 711-3. 